\title{
Influence of Sociodemographic Factors on Oral Hygiene Perception and Practices Among Pregnant Women
}

Lubna Ali ${ }^{1}$

Ahmed Moiz ${ }^{2}$

Hamna Abdul Samad ${ }^{3}$

Sadaf Saeed $^{4}$

Rumman Shahid $^{5}$

\author{
MBBS, MCPS, FCPS \\ BDS \\ BDS \\ BDS \\ BDS
}

OBJECTIVES: To assess the influence of sociodemographic factors on the knowledge, attitudes \& practices of pregnant women regarding oral hygiene, \& investigate whether women have any concept of oral health problems related to pregnancy.

METHODOLOGY: The present research of cross-sectional and non-experimental study design was conducted at the Gynaecology and Obstetrics Department of Ruth Pfau Civil Hospital Karachi, after obtaining approval from the Institutional Review Board (IRB), from 570 patients visiting the Gynecology OPD. All the patients were interviewed using a questionnaire based on different questions regarding socio-demographics, clinical variables (health status, gestation period, previous pregnancies) \& knowledge, attitude \& practice of oral health. Data was analyzed statistically using SPSS version 16.0. RESULTS: Majority (88.3\%) of the women belong to a low socio-economic status. When asked about dental problems during pregnancy, $44.8 \%$ experienced dental pain, $36.5 \%$ experienced gum bleeding, \& $18.7 \%$ experienced gum swelling. Approximately two-thirds $(62.6 \%$ ) had never visited a dentist, of which $50.2 \%$ perceived that they did not feel the need to go to the dentist, while 47.1 expressed fear \& high fees to be a barrier. Another significant finding was that only $40.8 \%$ would refer to dentist if they had any dental problem during pregnancy, while the rest would self-medicate or ask a family member $(25.9 \%)$, refer to a family doctor (17.6\%) or their gynecologist (15.7\%). Furthermore, an astonishing $66.9 \%$ did not agree that there is a link between oral health \& pregnancy.

CONCLUSIONS: The results of the study indicate lack of awareness regarding oral health and misconceptions about oral health problems during pregnancy. Education \& enlightenment of pregnant woman in terms of oral health \& dental care is crucial, for which the preliminary step is to establish a method of spreading awareness regarding the proven relationship between oral health \& pregnancy.

Key Words: Pregnancy oral health awareness knowledge women.

HOW TO CITE: Ali L, Moiz A, Samad HA, Saeed S, Shahid R. Influence of sociodemographic factors on oral hygiene perception and practices among pregnant women. J Pak Dent Assoc 2018;27(2):76-81.

DOI: https://doi.org/10.25301/JPDA.272.76

Received: 09 November, 2017, Accepted: 09 March, 2018

\section{INTRODUCTION}

$\mathrm{D}$ uring the period of gestation, women encounter a myriad of emotional and physiological disturbances and changes in various parts of their body. The significant levels of hormonal changes experienced by pregnant women introduce variations and complications in several regions of the body, including the oral cavity. The

1. Associate Professor, Department of Gynae \& Obs, Civil Hospital Karachi.

2. House Officer, Department of Dental (DIKIOHS), Dow University of Health Sciences.

3. House Officer, Department of Dental (DIKIOHS), Dow University of Health Sciences.

4. House Officer, Department of Dental (DIKIOHS), Dow University of Health Sciences.

5. House Officer, Department of Dental (DIKIOHS), Dow University of Health Sciences.

Corresponding author: "Dr. Ahmed Moiz" < ahmed.mz93@gmail.com > oral cavity is subjected to a lot of changes and disturbances during pregnancy, of which periodontal changes are the mostcommonly experienced and linked with the state of pregnancy. ${ }^{1}$

Most antenatal clinics and gynaecological/obstetric clinics and hospital wards do not routinely perform oral health screening on pregnant women, and a lack of implementation of standardized guidelines ensuring regular screening of nursing mothers has also been noted. ${ }^{2}$ As a consequence, antenatal clinics do not bring gestating and nursing women's attention towards the need for screening and identifying dental problems, nor are they then referred to specialized dental professionals for subsequent management 
and treatment of these dental problems. These findings indicate the growing need for creating awareness amongst gestating women regarding the need for caring for their oral hygiene, which will consequently have dire impacts on their overall health, as well as the health and well-being of their baby. ${ }^{3}$

In terms of dental health care administered during pregnancy, the foremost objective is the establishment and maintenance of a healthy oral environment in the mouth through regular tooth brushing for the control of plaque, flossing to prevent food remnants being stuck between teeth and encouraging growth of bacterial colonies, and professional prophylaxis (involving root planning, scaling and polishing) to keep significant oral health problems such as dental caries and periodontal disease at bay. ${ }^{4}$

Pregnancy has been established by various studies to propagate the occurrence and severity of oral problems in women. Pregnant women have time and again demonstrated a higher incidence of gingival inflammation and other signs of gingival disease as compared to women who are not pregnant. $^{5}$

The socio-cultural status and characteristics of any pregnant woman in question is also learned to be a factor impacting her periodontal conditions, with hormonal changes, and overall systemic health being other factors. ${ }^{6}$

Periodontal disease may emanate in the oral cavity as either gingivitis or persistent gingival inflammation, or as periodontitis. Gingivitis is an acute inflammation of the soft tissues surrounding teeth, however there is no incidence of periodontal attachment loss. On the other hand, periodontitis involves the chronic inflammation and steady destruction of the soft tissues which support the teeth and keep them attached. ${ }^{7}$

Of these two conditions, periodontal disease has been found through numerous researches ${ }^{8}$ to have negative and harmful impacts on the outcomes of the pregnancy. Incidence of periodontal disease has also been linked to lack of education and lower socio-economic conditions. ${ }^{9}$

Pregnant women are more vulnerable to developing periodontal disease as a result of greater concentrations of the hormones oestrogen and progesterone in the body. These hormonal variations lead to hyperaemia, oedema, and bleeding in the soft tissues surrounding and supporting the teeth. The periodontal tissues are subsequently more susceptible to invasion by bacterial colonies. Women belonging to higher socio-economic status are typically more educated and have greater access to knowledge and information pertaining to health, as well as greater exposure to healthcare professionals including dental professionals. As a result, they possess greater awareness regarding oral health care particularly during pregnancy and are more likely to be aware of and careful regarding oral health problems in pregnancy.

Studies have however, indicated that dental caries and periodontal disease both remain prevalent among pregnant women, particularly among those women who belong to ethnic or racial minorities and disadvantaged groups. ${ }^{10}$

Oral diseases are significantly prevalent worldwide, an impact a large proportion of the world's population. As a result, they also inflict an unavoidable impact in terms of morbidity and mortality as well. The existing burden of oral diseases is largely concentrated among poor and disadvantaged populations, and this fact brings to like the "inverse care law". ${ }^{11}$ Oral disease is considered to be the fourth most expensive ailment to treat, yet it has a significant impact on the Quality of Life of any individual. Women who come from a low income background with only a single earning family member in the household, are more disadvantaged in terms of seeking dental care, and their Quality of Life is therefore impacted even more. Low socioeconomic factors, therefore, in addition to the level of mother's education, are the main factors which cause a reduction in Quality of Life as a direct consequence of oral disease. ${ }^{12}$

The perception and understanding of oral health problems has been perceived to be an interfering factor for achievement of maternal oral health. The process of perception enables individuals to become enlightened regarding any situation, and they are then better able to interpret any information pertaining to it and are empowered to make choices regarding the situation. However, perception is essentially subjective in nature because it does not always accurately reflect the true nature of the situation. How an individual perceives their oral health is, albeit, one of the established measures of understanding the value that individual attaches to his/her oral health, and it also indicates their likelihood of seeking professional oral care to achieve optimal oral health status. ${ }^{13}$

Illogical perceptions are brought about due to several factors, largely due to irrational beliefs borne from old traditions and cultures and socio-economic and socio-cultural factors. In developing nations such as Pakistan, the population has generally been found through a number of previous studies to consider signs and symptoms of waning oral health to be less important than indications of general physiological illness. ${ }^{14}$ Many people also garner false beliefs and perceptions towards oral treatments and their consequences. Resultantly, they are more prone to avoid or delay seeking out and obtaining oral care, and this leads to exacerbation of the problem, eventually to levels that threaten the Quality of Life or even, in some cases, life itself.$^{15}$

The present study was designed in order to develop an informed understanding of the status of oral health awareness 
through investigating the oral health perceptions and practices during pregnancy among the women of Karachi, Pakistan. The study was thus conducted at a major government-funded tertiary care hospital which is frequented by the general, mixed population of Karachi. The majority of the patients who participated in the survey hailed from a lower socioeconomic background. This tertiary care hospital caters around 200-300 pregnant patients each month. Most of the women who frequented the hospital to visit the obstetrics and gynaecology department reported to living in rental houses, and reported being housewives who are completely dependent on a single earning member (usually their husband) of their family.

\section{METHODOLOGY}

The present research of cross-sectional and nonexperimental study design was conducted at the Gynaecology and Obstetrics Department of Ruth Pfau Civil Hospital Karachi. The study was conducted subsequent to its approval by IRB (168/DUHS/approval/2016/197). The study design was a self-administered, language friendly questionnaire survey, provided to women at random. The questionnaire interviewed all patients by asking various questions regarding sociodemographic and clinical variables. Women were asked to complete a questionnaire on their general and oral health which specifically targeted aspects regarding their oral hygiene, the level of dental care they employ on a regular basis, their sociodemographic details and other clinical variables which covered their health status, gestation period, previous pregnancies and knowledge, attitude \& practice of oral hygiene during pregnancies. They were given an opportunity to rate oral and general health related questions on a well split point scale of 0-10, with scores 1-3 being 'Mild', 3-6 'Moderate' and 6- 10 'Severe'. The sample size is calculated at $95 \%$ confidence with allowable error of $10 \%$. The sample size comprised of 570 pregnant women who were assisted in filling of the questionnaires with complete information to the best of their knowledge and the questionnaire also comprised an option of "Don't know" to prevent biased information. The data collected via the questionnaires was entered into and analysed statistically using SPSS version 16.0.

\section{RESULTS}

A total of 570 pregnant women, with mean age 23.8 (+/- 5.2 years) were involved in the study. Approximately half of women $(46.4 \%)$ were illiterate, while $28.2 \%$ had studied till primary level, and $14.2 \%$ had studied till higher secondary level or beyond. Tobacco consumption was comparatively higher in the lower socio-economic class, it was highlighted amongst the pregnant women where $15 \%$ had a habit of chewing ghutka or mawa, $12 \%$ were addicted to naswar, and $11.2 \%$ reported being addicted to pan or chhalia.

Two-third $(59.2 \%)$ of the study subjects belonged to a low socio-economic background. Whereas out of the remaining percentage, $29.1 \%$ represented lower middle class, $8.5 \%$ upper middle class, while $3.2 \%$ of the patients came from a high socio-economic class.

When asked about housing; $46.2 \%$ lived in a rental house, while $53.8 \%$ owned their houses. Approximately onethird of the women had access to boiled drinking water while an overwhelming majority of $71.3 \%$ used tap water for drinking purposes, which does not contain any fluoride or chlorine. Half of the women (51.8\%) had only one earning member in their family, whereas $19.6 \%$ of the women reported having two earning members in the family.
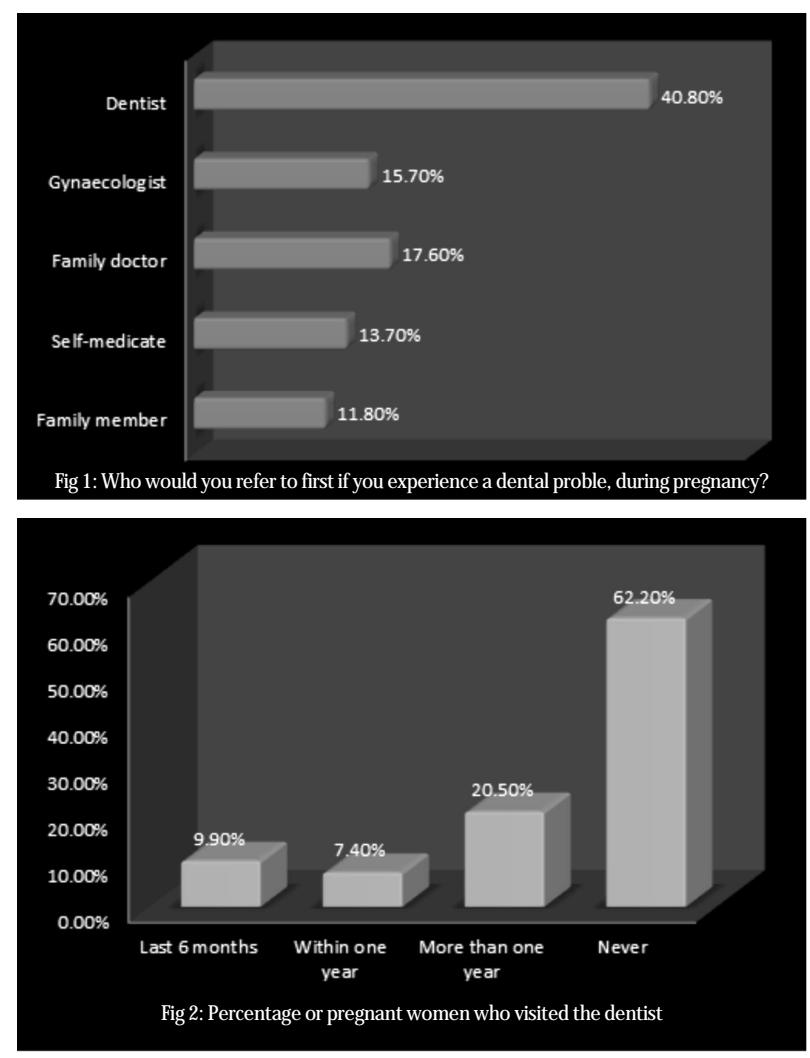

Generally, the most frequently experienced oral health problems among the pregnant women were dental pain (toothache) (43.6\%), bleeding gums (34.6\%) and swollen gums (19\%).

Bleeding gums, which was reported as one of the more common complaints among pregnant women, occurred in $34.6 \%$ out of which $17.5 \%$ had experienced it in the last 6 months. Out of all the women who responded to the survey, 
Table 1: Sociodemographic Data

\begin{tabular}{|l|l|c|c|}
\hline & Response & Frequency(N) & Percent (\%) \\
\hline Residence & Own & 294 & 51.5 \\
\hline No of children & Rental & 252 & 44.1 \\
\hline Monthly Income & two or less & 273 & 47.8 \\
\hline & three or more & 95 & 16.8 \\
\hline & 5000 or less & 50 & 8.8 \\
\hline Educational Status & 10000 or less & 188 & 32.9 \\
\hline & 20000 or less & 94 & 16.5 \\
\hline & $>$ than 20000 & 20 & 3.5 \\
\hline Illiterate & 254 & 44.5 \\
\hline Drinking Water & Primary school or & & 37.8 \\
\hline & more & 216 & 13.7 \\
\hline Socioeconomic status & High school or more & 78 & 70.4 \\
\hline & Unboiled & 402 & 28.4 \\
\hline & Boiled & 162 & 56.4 \\
\hline & Lower class & 322 & 28.7 \\
\hline & Lower middle class & 164 & 8.4 \\
\hline & High middle class & 48 & 3.2 \\
\hline & High class & 18 & \\
\hline
\end{tabular}

Table 2: Awareness of women regarding dental health during pregnancy

\begin{tabular}{|l|c|c|c|}
\hline Question & Agree & Disagree & $\begin{array}{c}\text { Don't } \\
\text { Know }\end{array}$ \\
\hline Pregnancy is a cause of gum problems & $\begin{array}{c}92 \\
(16.3 \%)\end{array}$ & $\begin{array}{c}336 \\
(58.8 \%)\end{array}$ & $\begin{array}{c}138 \\
(24.4 \%)\end{array}$ \\
\hline Pregnancy predisposes to tooth loss & $48(8.5 \%)$ & $\begin{array}{c}382 \\
(67.5 \%)\end{array}$ & $136(24 \%)$ \\
\hline Dental visit is unnecessary during pregnancy & $144(25.6)$ & $240(49.8)$ & $138(24.6)$ \\
\hline Every painful tooth should be removed & $170(30.4)$ & $\begin{array}{c}290 \\
(51.8 \%)\end{array}$ & $\begin{array}{c}100 \\
(17.9 \%)\end{array}$ \\
\hline Visit to dentist are always unpleasant & $152(27 \%)$ & $\begin{array}{c}244 \\
(43.4 \%)\end{array}$ & $\begin{array}{c}168 \\
(29.8 \%)\end{array}$ \\
\hline Fruits and vegetables have no effect on teeth and gums & $(49.8 \%)$ & $\begin{array}{c}(30.7 \%) \\
(21.4 \%)\end{array}$ \\
\hline $\begin{array}{l}\text { Do you think there is a connection between oral health and } \\
\text { pregnancy }\end{array}$ & $\begin{array}{c}186 \\
(33.1 \%)\end{array}$ & $\begin{array}{c}174 \\
(31.4 \%)\end{array}$ & $\begin{array}{c}202 \\
(35.9 \%)\end{array}$ \\
\hline
\end{tabular}

Table 3: Experience during pregnancy

\begin{tabular}{|llrr|}
\hline Experiences during pregnancy & Response & Frequency(N) & Percentage \\
\hline & Yes & 244 & 42.7 \\
\hline & No & 316 & 55.3 \\
\hline Severity of pain & Mild & 76 & 13.3 \\
\hline & Moderate & 48 & 8.4 \\
\hline & Severe & 112 & 19.6 \\
\hline Experienced gum bleeding & Yes & 196 & 34.3 \\
\hline & No & 370 & 64.8 \\
\hline Experienced gum swelling & Yes & 102 & 17.9 \\
\hline & No & 464 & 81.3 \\
\hline Visited dental clinic & Never & 352 & 61.6 \\
\hline & Within one year & 98 & 17.2 \\
\hline & more than one year & 116 & 20.3 \\
\hline
\end{tabular}

$62.2 \%$ had never visited a dentist, while $20.5 \%$ visited more than one year ago and only $9.9 \%$ had visited during the last six months.

Upon being questioned regarding their brushing habits, $35.5 \%$ responded that they brushed their teeth twice a day, $45.8 \%$, responded that they brush once a day, and $15.8 \%$ reported that they are not habitual of brushing. As for the cleaning aids used for brushing, $70.31 \%$ used a tooth brush, $25.51 \%$ responded that they used dandasa/miswak, while only $2.27 \%$ of the respondents reported use of dental floss/mouth wash. When asked about the barriers to visiting the dentist; $50.2 \%$ did not feel any need to visit the dentist, $30.4 \%$ chose fear of dentist to be a barrier, $16.7 \%$ mentioned high fees while $2.7 \%$ of the women responded that they had encountered permission issues.

Upon being asking for their opinion regarding who they would choose to consult in case of dental emergency; $11.8 \%$ said they would refer to their family members, $13.7 \%$ responded that they would choose to self-medicate, $17.6 \%$ said that they would refer to a family doctor for their dental problems, and $15.7 \%$ said that they would consult a gynaecologist. Only $40.8 \%$ of the respondents said that they would opt to consult a dentist in the event of a dental emergency. Out of the total number of respondents, $25.6 \%$ perceived that dental visits are unnecessary during pregnancy, while $24.6 \%$ did not know whether dental visits were necessary or not.

\section{DISCUSSION}

The general results and overall response of the patient population at Civil Hospital Karachi suggested that there is a pressing need for interventions in order to increase awareness regarding the maintenance of oral health and hygiene. The questions were structured to assess the awareness and oral hygiene practices among the pregnant women frequenting a local general hospital. Majority of the patients interviewed hailed from rural areas, and from a low socioeconomic background. The results showed that $71 \%$ of the women used tap water for drinking, demonstrating the lack of awareness in regards to the significance of chlorine and fluoride levels in the water.

\section{Perceived Barriers}

Analogous to the outcome of our results (50.2\%), most of the women surveyed in another similar study did not consider it important to have a dental check-up during pregnancy. ${ }^{6}$ Another comparable study deduced that the most common reasons for gestating women to not go to the dentist were, "I was not having a problem," (89\%), and "I chose to delay until after pregnancy," (68\%) (Habashneh et al., 2005). ${ }^{16}$

According to Lee et al. (2010), there are five perceived barriers, mostly related to attitude, associated with reluctance among dentists from it providing dental care to pregnant women. Such barriers include time over consciousness, economic reasons, deficiency in professional skills, dental staff resistance, and peer pressure(Lee et al., 2010). ${ }^{17}$ It was the perception of $25.6 \%$ of the respondents that dental visits 
are unnecessary during pregnancy, whereas $24.6 \%$ of the women did not know whether dental visits hold any significance or not.

\section{Socioeconomic disparities}

Approximately one-third of the women had access to boiled drinking water while an overwhelming majority of two-third used tap water for drinking purposes. Some workers have emphasized on the importance of good oral health in pregnancy, suggesting that it is advantageous to both the mother and her baby. For instance, maternal periodontal disease has often been linked to preterm birth, low birth weight, and preterm low birth weight (Mills \& Moses, 2002; Dasanayake et al. 2008). ${ }^{18}$

\section{Misconceptions}

Pregnant women are often subject to misconceptions pertaining to their oral health during pregnancy, which acts as one of the most significant barriers preventing them from seeking dental care. Among these misconceptions, brought about by lack of awareness, are the beliefs that compromised oral health and hygiene is usual and an accepted consequence of pregnancy, or provision of dental treatment during pregnancy will bring harm to the foetus (George et al., 2011). ${ }^{19}$

Among the perceived barriers noted by this study, the most predominant one was that most women were generally reluctant to visit the dentist. A large percentage of the surveyed population (27\%) of the women found dental visits to be an unpleasant experience which they would rather avoid. The worrying lack of awareness among the women visiting the OPD was further highlighted by the fact that $30.47 \%$ reported that it is their understanding that every painful or problematic tooth should be removed.

The majority of mothers surveyed in a study similar to the present research had also reported that they did not seek treatment from a dentist during the time of their pregnancy because they had no dental complaints (Saddki, Yusoff, \& Hwang, 2010).$^{20}$ Other studies indicate that nearly half of the pregnant women with dental problems sought no dental care for them (Lydon-Rochelle, Krakowiak, Hujoel, \& Peters, $2004)^{21}$ or deliberately postponed any impending dental visits until after the pregnancy (Dinas et al., 2004). ${ }^{22}$

\section{CONCLUSIONS}

Pregnancy serves as a "teachable moment" for gestating women, and is an opportunity for women to become educated and enlightened regarding self-oral-care, and future childcare in terms of oral health. There is a significant need to prioritize an educational intervention for mothers who are suffering from oral health problems during pregnancy. In this way, they will also learn to effectively prevent the development of these diseases in their children.

There is a critical need to bring to focus the power of prevention in this regard, as both dental caries as well as periodontal disease are largely preventable so long as wellrecognized, established strategies are implemented. The results of the study indicate lack of awareness regarding oral health and misconceptions about oral health problems during pregnancy. Education \& enlightenment of pregnant woman in terms of oral health \& dental care is crucial, for which the preliminary step is to establish a method of spreading awareness regarding the proven relationship between oral health \& pregnancy.

\section{CONFLICT OF INTEREST}

None declared

\section{REFERENCES}

1. Amar S, Chung KM. Influence of hormonal variation on the periodontium in women periodontol 2000. 1994;6(1): 79-87.

https://doi.org/10.1111/j.1600-0757.1994.tb00028.x

2. Gaffield ML, GILBERT BJ, MALVITZ DM, ROMAGUERA R. Oral health during pregnancy: an analysis of information collected by the pregnancy risk assessment monitoring system. J Am Dent Assoc. 2001;132 (7): 1009-16.

https://doi.org/10.14219/jada.archive.2001.0306

3. George A, Johnson M, Blinkhorn A, Ellis S, Bhole S, Ajwani S. Promoting oral health during pregnancy: current evidence and implications for Australian midwives. J Clin Nurs. 2010;19(23-24):3324-33. Silk, Hugh, Alan B. Douglass, Joanna M. Douglass, and Laura Silk. "Oral health during pregnancy." American Family Physician 77, no. 8 (2008).

4. Kloetzel MK, Huebner CE, Milgrom P. Referrals for dental care during pregnancy. J Clin Midwifery Women Health. 2011;56(2):110-7.

https://doi.org/10.1111/j.1542-2011.2010.00022.x

5. Boggess KA, Society for Maternal-Fetal Medicine Publications Committee. Maternal oral health in pregnancy. Obstet Gynecol. 2008;111(4):976-86.

https://doi.org/10.1097/AOG.0b013e31816a49d3

6. Hajishengallis G. Periodontitis: from microbial immune subversion to systemic inflammation. Nature Reviews Immunol. 2015;15(1):30-44.

https://doi.org/10.1038/nri3785

7. Kloetzel MK, Huebner CE, Milgrom P. Referrals for dental care during pregnancy. J Midwifery Women Health. 
2011;56(2):110-7. https://doi.org/10.1111/j.1542-2011.2010.00022.x 8. Buchwald S, Kocher T, Biffar R, Harb A, Holtfreter B, Meisel P. Tooth loss and periodontitis by socio-economic status and inflammation in a longitudinal population-based study. J Clin Periodontol. 2013;40(3):203-11. https://doi.org/10.1111/jcpe.12056

9. Reisine ST, Fertig J, Weber J, Leder S. Impact of dental conditions on patients' quality of life. Community Dent Oral Epidemiol. 1989;17(1):7-10.

https://doi.org/10.1111/j.1600-0528.1989.tb01816.x

10. Hom JM, Lee JY, Divaris K, Baker AD, Vann WF. Oral health literacy and knowledge among patients who are pregnant for the first time. J Am Dent Assoc. 2012; 143(9):972-80.

https://doi.org/10.14219/jada.archive.2012.0322

11. Fiscella K, Shin P. The inverse care law: implications for healthcare of vulnerable populations. J Ambulat Care Manag. 2005;28(4):304-12.

https://doi.org/10.1097/00004479-200510000-00005

12. Conger RD, Conger KJ, Martin MJ. Socioeconomic status, family processes, and individual development. J Marr Fam. 2010;72(3):685-704.

https://doi.org/10.1111/j.1741-3737.2010.00725.x

13. Rigo L, Dalazen J, Garbin RR. Impact of dental orientation given to mothers during pregnancy on oral health of their children. Einstein (São Paulo). 2016;14(2):219-25. https://doi.org/10.1590/S1679-45082016AO3616

14. Khan SA, Dawani N, Bilal S. "Perceptions and myths regarding oral health care amongst strata of low socio economic community in Karachi, Pakistan." J Pak Med Assoc 2012;62:1198-1203.

15. Reisine ST, Fertig J, Weber J, Leder S. Impact of dental conditions on patients' quality of life. Community Dent Oral Epidemiol. 1989;17(1):7-10. https://doi.org/10.1111/j.1600-0528.1989.tb01816.x

16. Al Habashnesh, R., Guthmiller, J.M., Levy, S., Johnson, G.K., Squier, C., Dawson, D.V. \&

17. Lee RS, Milgrom P, Huebner CE, Conrad DA. Dentists' perceptions of barriers to providing dental care to pregnant women. Women's Health Issues. 2010;20(5):359-65.2. 18. Dasanayake AP, Gennaro S, Hendricks-Mu-oz KD, Chhun N. Maternal periodontal disease, pregnancy, and neonatal outcomes. MCN: Am J Mat Child Nurs. 2008; 33(1):45-9.

https://doi.org/10.1097/01.NMC.0000305657.24613.47 19. George, A., Johnson, M., Duff, M., Ajwani, S., Bhole, S., Blinkhorn, A., \& Ellis, S. (2011). Midwives and oral health care during pregnancy: perceptions of pregnant women in south-western Sydney, Australia. J Clin Nurs, 21(7-8), 1087-1096.

https://doi.org/10.1111/j.1365-2702.2011.03870.x

20. Saddki N, Yusoff A, Hwang YL. Factors associated with dental visit and barriers to utilisation of oral health care services in a sample of antenatal mothers in Hospital Universiti Sains Malaysia. BMC Public Health. 2010 Feb 18;10(1):75.

https://doi.org/10.1186/1471-2458-10-75

21. Lydon-Rochelle MT, Krakowiak P, Hujoel PP, Peters RM. Dental care use and self-reported dental problems in relation to pregnancy. AM J Public Health. 2004;94(5): 765-71. https://doi.org/10.2105/AJPH.94.5.765

22. Dinas K, Achyropoulos V, Hatzipantelis E, Mavromatidis G, Zepiridis L, Theodoridis T, Dovas D, Tantanasis T, Goutzioulis F, Bontis J. Pregnancy and oral health: utilisation of dental services during pregnancy in northern Greece. Acta Obstet Gynecol Scan. 2007;86(8):938-44. https://doi.org/10.1080/00016340701371413 